\title{
Movement of the $\beta$-hairpin in the third zinc-binding module of UvrA is required for DNA damage recognition
}

Thanyalak Kraithong a,b,1, Ketsaraphorn Channgamª, ${ }^{\mathrm{a}, \mathrm{b}, 1}$, Ornchuma Itsathitphaisarnn ${ }^{\mathrm{a}, \mathrm{c}}$, Montip Tiensuwand David Jeruzalmie , and Danaya Pakotiprapha ${ }^{a, b, *}$

\section{Keywords:}

UvrA, nucleotide excision repair, disulfide crosslinking, NER

\section{Abbreviations:}

A angstrom

ABC ATP binding cassette

ADP adenosine $5^{\prime}$ - diphosphate

ATP adenosine $5^{\prime}$ - triphosphate 
$\beta$-ME $\quad \beta$ - mercaptoethanol

bp base pair

BSA bovine serum albumin

Bst Geobacillus stearothermophilus

DNA 2'- deoxyribonucleic acid

dsDNA double-stranded DNA

EMSA electrophoretic mobility shift assay

IPTG isopropyl- $\beta$-D-thiogalactopyranoside

$\mathrm{NADH}$ nicotinamide adenine dinucleotide

NER nucleotide excision repair

$\mathrm{OD}_{600} \quad$ optical density at $600 \mathrm{~nm}$

PAGE polyacrylamide gel electrophoresis

PMSF phenylmethylsulfonyl fluoride

Tris Tris(hydroxymethyl)aminomethane

U unit

UV ultraviolet

Zn3hp $\quad \beta$-hairpin of the third Zn-binding module 


\begin{abstract}
Nucleotide excision repair (NER) is distinguished from other DNA repair pathways by its ability to process various DNA lesions. In bacterial NER, UvrA is the key protein that detects damage and initiates the downstream NER cascade. Although it is known that UvrA preferentially binds to damaged DNA, the mechanism for damage recognition is unclear. $A \beta$-hairpin in the third $Z n$-binding module ( $Z n 3 h p)$ of UvrA has been suggested to undergo a conformational change upon DNA binding, and proposed to be important for damage sensing. Here, we investigate the contribution of the dynamics in the Zn3hp structural element to various activities of UvrA during the early steps of NER. By restricting the movement of the Zn3hp using disulfide crosslinking, we showed that the movement of the $\mathrm{Zn} 3 \mathrm{hp}$ is required for damagespecific binding, UvrB loading and ATPase activities of UvrA. We individually inactivated each of the nucleotide binding sites in UvrA to investigate its role in the movement of the Zn3hp. Our results suggest that the conformational change of the Zn3hp is controlled by ATP hydrolysis at the distal nucleotide binding site. We propose a bi-phasic damage inspection model of UvrA in which movement of the Zn3hp plays a key role in damage recognition.
\end{abstract}




\section{Introduction}

Discrimination of damaged from native DNA is a problem solved by all DNA repair pathways. In nucleotide excision repair (NER), this problem is more challenging owing to the highly divergent nature of the lesions handled. In bacterial NER, damage recognition and strand incision are carried out by the UvrA, UvrB and UvrC proteins. UvrA and UvrB assemble into the damage sensing complex $\left(A_{2} B_{2}\right)$ that patrols the genome, and, in an ATP dependent manner, determines whether the sampled DNA is damaged. Within the complex, UvrA is the main agent that implements the discrimination function. Indeed, UvrA alone is capable of distinguishing damaged from undamaged DNA in vitro [1, 2]. Once damaged DNA has been located, UvrA exits the damage sensing complex, and UvrB takes its place at the lesion [3]. UvrB, in turn, recruits the UvrC endonuclease to DNA, leading to cleavage on either side of the lesion $[4,5]$. Subsequently, UvrD, DNA polymerase I and DNA ligase restore the original DNA sequence $[6,7]$.

UvrA belongs to the ATP-binding cassette (ABC) family of ATPases [8]. The proteins in this family bind two nucleotides in composite binding sites at the interface between two domains; these are often referred to as the RecA-like domain and the helical domain in $A B C$ transporters [9, 10]. In UvrA, the equivalent domains are termed the ATP-binding domain and signature domain, respectively [11]. The ATPbinding domain contributes the Walker $\mathrm{A}$ and $\mathrm{B}$ motifs, whereas the signature domain contributes the $A B C$ signature motif to the nucleotide binding site. UvrA is distinguished from most other members of the family in that it is a tandem ABC ATPase, harboring two sets nucleotide binding motifs, which are used to form two composite nucleotide binding sites in an intramolecular manner [11].

Structural analyses of UvrA and the $\mathrm{UvrA}_{2} \mathrm{UvrB}_{2}$ damage sensing complex have revealed two distinct conformers of the UvrA dimer, termed 'open tray' and 'closed groove' [12] (Fig. 1), that differ significantly in the arrangement of the protomers within the UvrA dimer. Six structures of UvrA have been described in the 'open tray' configuration [11, 13-15], and one in the 'closed groove' conformation [12]. Although one of the UvrA structures in the 'open tray' configuration includes lesion-containing DNA [13], the precise mechanisms for the recognition of damaged DNA remain to be elucidated. In addition, despite showing the same relative 
orientation of the two protomers within the dimer, at least three of the 'open tray' structures [11-13] differ in the conformations of the signature domain II; this feature could be of potential mechanistic significance (Fig. 1, and supplementary Fig. 1). Neither the relative orientation of the protomers nor the conformation of the signature domain II shows clear relationship with the nucleotide that is bound in the structure. However, we note that none of the available structures were determined in complex with ATP.

Here, we focus on a conserved structural element within the signature domain II of UvrA, a $\beta$-hairpin in the Zn module 3 (hereafter referred to as Zn3hp) [11]. UvrA possesses three $\mathrm{Zn}$-binding modules not found in other ABC ATPases. The first two Zn modules are located in the signature domain I [11] and will not be discussed further. Comparison of various UvrA structures, in both the open tray and closed groove conformations, revealed that the Zn3hp can adopt at least three conformations due to the rotation of the signature domain II (Fig. 1, Supplementary Table 1 and Supplementary Fig. 1 [16]).

To set a specific frame of reference for the position of the Zn3hp, we define the conformation of the Zn3hp in the ADP-bound UvrA structure from Geobacillus stearothermophilus (Bst) (Fig. 2A) [11] that are in vicinity of each other as the 'hairpin-closed' conformation. This conformation has been observed in both the open tray and closed groove dimer configurations [12, 14, 15] (Fig. 1, Supplementary Fig. 1B). On the other hand, the term 'hairpin-open' conformation will refer to the conformation of the Zn3hp in the DNA-bound UvrA structure [13] (Fig. 2B), in which the signature domain II undergoes an $18.5^{\circ}$ rotation relative to that in the ADP-bound structure to accommodate the DNA (Fig. 2C, Supplementary Fig. 1, and Supplementary Table 1) [13]. As a result, the tip of the Zn3hp moves $21 \AA$ further away from the dimer interface during DNA binding. The third conformation, which is intermediate between the 'hairpin-closed' and 'hairpin-open' states, is observed in the truncated BstUvrA structure (3UX8) [12]. While the Zn3hp is disordered in this structure, the $16.2^{\circ}$ rotation of the signature domain II with respect to the ADP-bound structure implies that the Zn3hp moves further away from the dimer interface (Fig. 1 and Supplementary Fig. 1A). 
In addition to structural evidence, previous biochemical and genetic studies underscore the importance of the Zn3hp in the discrimination of damaged from undamaged DNA. For example, a deletion mutant of Bacillus caldotenax UvrA that lacks the Zn3hp (a $\Delta$ Zn3hp mutant, also known as the 'ZnG mutant' [17]) binds to DNA with higher affinity than wild-type UvrA, however, it fails to discriminate between damaged and undamaged DNA [17]. In addition, the deletion of the hairpin compromises other steps of NER, including UvrB loading and damage incision, when undamaged double-stranded DNA (dsDNA) was added to the reaction as a competitor [17]. Deletion of the Zn3hp also alters the ATPase activity of UvrA in comparison to wild-type UvrA from both B. caldotenax [17] and Escherichia coli [18]. Lastly, E. coli whose Zn3hp coding region had been deleted from the only copy of uvrA gene were rendered very sensitive to UV $[17,18]$. Collectively, these structural, biochemical, and genetic data imply a crucial role for the Zn3hp during NER.

Here, we show that the conformational dynamics that allow the Zn3hp to interconvert between the hairpin-closed and hairpin-open conformations are required for activity. To study the role of this dynamic segment, we introduced a disulfide crosslink between $\mathrm{H} 750 \mathrm{C}$ of each protomer to restrict the movement of the $\mathrm{Zn3hp}$ (Fig. 2A). Crosslinked H750C UvrA was assayed for its damage-specific DNA binding, UvrB loading, and ATPase activities. Our findings indicate that movement of the Zn3hp element is essential for damage sensing, ATP hydrolysis and UvrB loading. Moreover, crosslinking studies of ATPase-deactivated H750C UvrA mutants in which each of the ATP binding sites has been inactivated suggested that the movement of the $\mathrm{Zn} 3 \mathrm{hp}$ is controlled by the distal nucleotide binding site.

\section{Materials and methods}

\subsection{Plasmids}

Protein expression constructs used in this study are as follows:

BstUvrA (wild-type, H750C, K37A/H750C, and K643A/H750C), and BstUvrB (wild-type, and Cys-less (C211A/C144A/C303A)) in the pET28a vector. 


\subsection{DNA substrates}

The sequences of 50-mer oligonucleotides used to create dsDNA substrates are as follows. The sites of damage are underlined.

Oligo-1:

5'-AGTTCTATGCGCACCGAATTCCCACTTGAACCCAAGCTTGCCGGGCCTCT-3' Oligo-2:

5'AGAGGCCCGGCAAGCTTGGGT CTTTTTGGGAATTCGGTGCGCATAGAACT-3' Oligo-3:

5'-TGGATTACTTACGGCCACATTACTACTGGAACTCAGAACGAGCTGACAGG-3'

Oligo-4:

5'-CCTGTCAGCTCGTTCTGAGTTCC_GTAGTAATGTGGCCGTAAGTAATCCA-3' Oligo-5:

5'-CCTGTCAGCTCGTTCTGAGTTCCAGTAGTAATGTGGCCGTAAGTAATCCA-3'

Oligo-6:

5'-GGATTACTTACGGCCACACATATAA/iAlex488N/

TTATATCAGAACGAGCTGACAGGT-3'

Oligo-7:

5’ACCTGTCAGCTCGTTCTGATATAATTTATATGTGTGGCCGTAAGTAATCC3’

Oligo- 1 and 2 were annealed by heating to $95^{\circ} \mathrm{C}$ for 10 minutes in annealing buffer (10 mM Tris-HCl pH 8.0, $50 \mathrm{mM} \mathrm{NaCl}, 1 \mathrm{mM}$ EDTA) followed by slow cooling to room temperature, resulting in a DNA fragment containing a five-nucleotide mismatch. Oligo-3 was annealed with either Oligo-4 or 5 to get a DNA fragment with a single-nucleotide gap or undamaged DNA, respectively. Alexa488-containing DNA was obtained by annealing Oligo- 6 and 7 . 


\subsection{Protein expression and purification}

\subsubsection{Protein expression}

UvrA and UvrB were expressed in E. coli BL21(DE3) pLysS. The cells were grown at $37^{\circ} \mathrm{C}$ until $\mathrm{OD}_{600}$ reached 0.6 , then $0.5 \mathrm{mM}$ Isopropyl- $\beta$-Dthiogalactopyranoside (IPTG) was added to induce protein expression. The cells were grown for additional 14 hours and harvested by centrifugation. The pellet was resuspened in lysis buffer (50 mM sodium phosphate $\mathrm{pH} 8.0,500 \mathrm{mM} \mathrm{NaCl}$ and 10 $\mathrm{mM}$ imidazole) and stored at $-80^{\circ} \mathrm{C}$ until use.

\subsubsection{Purification of UvrA and UvrB}

The cells were thawed at $4^{\circ} \mathrm{C}$. Before cell lysis by sonication, $1 \mathrm{mM}$ phenylmethylsulfonyl fluoride (PMSF) was added into the thawed cells in the lysis buffer. The cell lysate was clarified by centrifugation at $25,000 \times \mathrm{g}$ for 30 minutes at $4^{\circ} \mathrm{C}$. The clarified cell lysate was incubated with nickel-nitrilotriacetic acid (Ni-NTA) agarose beads (Qiagen). Unbound proteins were removed by washing buffer (20 $\mathrm{mM}$ imidazole in $50 \mathrm{mM}$ sodium phosphate $\mathrm{pH} 8.0,500 \mathrm{mM} \mathrm{NaCl}$ ). Proteins were eluted with $250 \mathrm{mM}$ imidazole in $50 \mathrm{mM}$ sodium phosphate $\mathrm{pH} 8.0,500 \mathrm{mM} \mathrm{NaCl}$. Next, UvrA was purified by Heparin Sepharose Fast Flow (GE Healthcare Life Sciences) with a linear gradient of 0.25-1.2 M NaCl in Buffer $\mathrm{A}(25 \mathrm{mM}$ Tris- $\mathrm{HCl} \mathrm{pH}$ 7.4, $5 \mathrm{mM} \beta$-mercaptoethanol ( $\beta$-ME)) while UvrB was purified by Q-Sepharose Fast Flow (GE Healthcare Life Sciences) with a linear gradient of $0.1-0.6 \mathrm{M} \mathrm{NaCl}$ in Buffer A.

Subsequently, both UvrA and UvrB were purified by Sephacryl S-300 (GE Healthcare Life Sciences) with GF buffer (25 mM Tris-HCl pH 7.4, $400 \mathrm{mM} \mathrm{NaCl}$ and

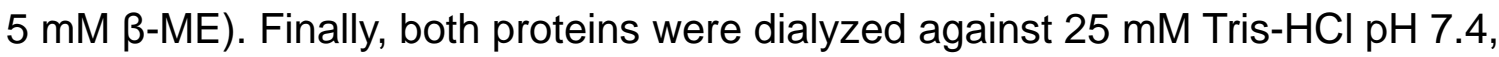
$250 \mathrm{mM} \mathrm{NaCl}, 20 \%$ (v/v) glycerol, and $5 \mathrm{mM} \beta-\mathrm{ME}$ and stored at $-80^{\circ} \mathrm{C}$.

\subsection{DNA binding assays}


DNA binding was analyzed by electrophoretic mobility shift assay (EMSA). This assay was performed by titrating $20 \mathrm{nM}$ DNA with a five-nucleotide mismatch or undamaged DNA (see 2.2) with 0-200 nM UvrA in $50 \mathrm{mM}$ Tris- $\mathrm{HCl} \mathrm{pH} \mathrm{7.5,50} \mathrm{mM}$ $\mathrm{NaCl}, 10 \mathrm{mM} \mathrm{MgCl}$, $1 \mathrm{mM} \mathrm{ATP,} \mathrm{5 \%} \mathrm{(v/v)} \mathrm{glycerol,} 0.1 \mathrm{mg} / \mathrm{ml}$ BSA. The reactions were incubated at $55^{\circ} \mathrm{C}$ for 30 minutes, chilled on ice, then analyzed on $6 \%$ native polyacrylamide gels containing $10 \mathrm{mM} \mathrm{MgCl}_{2}$ and $1 \mathrm{mM} \mathrm{ATP}$ in $0.5 \mathrm{X}$ Tris-borate. The gels were stained with SYBR-Gold (Invitrogen) and visualized by a Typhoon scanner (GE Healthcare Life Sciences) using an excitation wavelength of $488 \mathrm{~nm}$ and an emission wavelength of $520 \mathrm{~nm}$ with $40 \mathrm{~nm}$ bandwidth. Quantification of the band intensities was carried out using ImageQuant (GE Healthcare Life Sciences). DNA binding activities were shown as percentage of DNA bound, which was calculated from the ratio between intensity of the UvrA-DNA complex band and total intensity from all bands in each lane. For crosslink-reversed UvrA, $10 \mathrm{mM}$ of $\beta-\mathrm{ME}$ was added to the crosslinked protein at room temperature for 2 hours prior to the assay.

\subsection{UvrB loading assays}

UvrB loading was measured in $50 \mathrm{mM}$ Tris- $\mathrm{HCl}$ pH 7.5, $100 \mathrm{mM} \mathrm{NaCl}, 10 \mathrm{mM}$ $\mathrm{MgCl}_{2}, 1 \mathrm{mM} \mathrm{ATP}, 5 \%(\mathrm{v} / \mathrm{v})$ glycerol, and $0.1 \mathrm{mg} / \mathrm{ml}$ BSA. This assay was performed by titrating 10 nM Alexa488-labeled DNA substrate (see 2.2) and 5 nM UvrA with 0$200 \mathrm{nM}$ UvrB. The reactions were incubated at $55^{\circ} \mathrm{C}$ for 10 minutes, chilled on ice, then analyzed on $6 \%$ native polyacrylamide gels containing $10 \mathrm{mM} \mathrm{MgCl}_{2}$ and $1 \mathrm{mM}$ ATP in 0.5X Tris-borate. Bands were visualized by a Typhoon scanner (GE Healthcare Life Sciences) using an excitation wavelength of $488 \mathrm{~nm}$ and an emission wavelength of $520 \mathrm{~nm}$ with $40 \mathrm{~nm}$ bandwidth. Quantification of the band intensities was carried out using ImageQuant (GE Healthcare Life Sciences). UvrB loading activities were shown as percentage of DNA bound by UvrB, which was calculated from the ratio between intensity of the UvrB-DNA complex band and total intensity from all bands in each lane. For crosslink-reversed UvrA, $10 \mathrm{mM}$ of $\beta$-ME was added to the crosslinked protein at room temperature for 2 hours prior to the assay. 
The rate of ATP hydrolysis was measured using a coupled enzyme system consisting of pyruvate kinase (Sigma-Aldrich) and lactate dehydrogenase (SigmaAldrich), where ATP hydrolysis is coupled with NADH oxidation. Each $500 \mu$ reaction contained $4 \mathrm{U}$ lactate dehydrogenase, $2.5 \mathrm{U}$ pyruvate kinase, $2 \mathrm{mM}$ phosphoenolpyruvate (Sigma-Aldrich), $250 \mu \mathrm{l} / \mathrm{ml}$ bovine albumin serum (BSA), 0.16 mM NADH (Sigma-Aldrich) in $50 \mathrm{mM} \mathrm{K-HEPES} \mathrm{pH} \mathrm{7.5,} 150 \mathrm{mM}$ potassium acetate, $8 \mathrm{mM}$ magnesium acetate and $5 \mathrm{mM} \beta-\mathrm{ME}$. The reaction mixtures were incubated at $55^{\circ} \mathrm{C}$ for 5 minutes before $1 \mathrm{mM}$ ATP (Sigma-Aldrich) was added to start the reactions. A control reaction, without UvrA, was set up for background subtraction. The reactions were monitored for 30 minutes by measuring the decrease in $A_{340}$, which represents NADH oxidation coupled to ATP hydrolysis. Turnover numbers $\left(k_{c a t}\right),(\mathrm{mol}$ ATP $/ \mathrm{min} / \mathrm{mol}$ UvrA $) \pm$ standard error $(n=3)$ were reported. The effect of DNA on the rate of ATP hydrolysis was investigated by adding an equivalent of 10 $\mu \mathrm{M}$ bp of salmon sperm DNA (Invitrogen) into the assay. To reverse the crosslink, 10 $\mathrm{mM}$ of $\beta$-ME was added to the crosslinked protein for 2 hours prior to the assay.

\subsection{Crosslinking assays}

$\beta-M E$ was removed from UvrA-H750C by buffer exchange into the $\beta$-ME-free GF buffer using Sephadex G-25 columns (PD10 desalting columns from GE Healthcare Life Sciences). Crosslinking reactions were set up in the $\beta$-ME-free GF buffer using $1 \mu \mathrm{M}$ of UvrA-H750C monomer and factors involved in the damage recognition step, which include $1 \mu \mathrm{M}$ Cys-less UvrB, $0.5 \mu \mathrm{M}$ 50-bp DNA substrates (undamaged or damaged DNA with a single-nucleotide gap located in the middle of DNA) (see 2.2), and $1 \mathrm{mM}$ nucleotide (ATP or ADP) in $10 \mathrm{mM} \mathrm{MgCl}_{2}$. The reaction mixtures were incubated for 24 hours at room temperature. After 24-hour incubation, the reaction was stopped by adding non-reducing SDS-PAGE loading buffer with 20 $\mathrm{mM} \mathrm{N}$-ethylmaleimide. The samples were then analyzed on 10\% SDS-PAGE. Quantification of band intensities was carried out using ImageQuant (GE Healthcare Life Sciences). Percent crosslinking efficiency was calculated as crosslink band intensity $\times 100 /$ total UvrA intensities in each lane. Normalized crosslinking efficiency was calculated as crosslinking efficiency of each condition $\times 100 /$ crosslinking efficiency of no factor condition. Fold difference of crosslinking was 
calculated as percent crosslinking efficiency from condition with nucleotide (ATP or ADP) / percent crosslinking efficiency from condition without nucleotide.

\section{Results}

\subsection{The closed conformation of the Zn3hp was trapped by disulfide crosslinking at $\mathrm{H} 750 \mathrm{C}$.}

To better understand the role of the conformational change of the Zn3hp in the function of UvrA, its movement was restricted by a disulfide linkage. To this end, the Disulfide by Design program [19, 20] was employed to analyze the ADP-bound, 'hairpin-closed' structure of UvrA to determine pairs of residues with potential to form inter-molecular disulfide bonds between each $\mathrm{Zn3hp}$ that is located at the dimer interface. This analysis revealed that the cysteine substitution of $\mathrm{H} 750$ at the tip of each Zn3hp in BstUvrA (Fig. 2A) might allow the formation of such inter-molecular crosslinking that could influence DNA binding, ATPase and UvrB loading activities of UvrA. We propose that, as observed in the ADP-bound UvrA structure, the crosslinking would fix the Zn3hp in the hairpin-closed conformation (Fig. 2A). Once the crosslinking is reversed, however, the Zn3hp would be free to adopt either the hairpin-closed or the hairpin-open conformation, as observed in the DNA-bound structure of UvrA (Fig. 2B).

To prepare the crosslinked protein, the $\mathrm{H} 750 \mathrm{C}$ BstUvrA mutant was incubated under a non-reducing condition at room temperature for 24 hours. Such treatment resulted in approximately $80 \%$ crosslinking of $\mathrm{H} 750 \mathrm{C}$ UvrA (Fig. 2D). Wild-type UvrA was also included as a control. As expected, no crosslinked band was observed with the wild-type protein (Supplementary Fig. 2), indicating that the disulfide crosslink specifically forms at $\mathrm{H} 750 \mathrm{C}$, and that none of the twelve native cysteine residues are involved in disulfide linkage formation. Gel filtration analysis of the disulfide crosslinked $\mathrm{H} 750 \mathrm{C}$ UvrA showed that the crosslinked protein was eluted the same position as wild-type UvrA (Supplementary Fig. 3), which is natively a dimer, implying that the introduction of the disulfide linkage does not perturb the structure of the UvrA dimer. Since the crosslinked H750C UvrA could not be resolved from the uncrosslinked UvrA dimer using chromatographic techniques, the crosslinked H750C 
UvrA used in our experiments are crosslinked to approximately $80 \%$, unless stated otherwise.

\subsection{The mobility of the Zn3hp is crucial for binding to damaged, but not native DNA}

To investigate whether dynamics of the Zn3hp influences DNA binding and discrimination between native and damaged DNA, an electrophoretic mobility shift assay (EMSA) was employed to compare DNA binding activity of H750C UvrA that had been disulfide crosslinked at the mutated residue, and H750C UvrA in which the disulfide linkage had been reversed by treatment with $\beta-M E$. Our results showed that only binding to damaged DNA was disrupted by the disulfide crosslinking at $\mathrm{H} 750 \mathrm{C}$ while binding to native DNA was unaffected (Fig. 3 and Supplementary Fig. 4).

Given that the dissociation constant for binding between BstUvrA and damaged DNA is approximately $0.5 \mathrm{nM}$ [12] and UvrA binds to DNA as a dimer [1, $21,22]$, the $20 \mathrm{nM}$ damaged DNA substrate in the assay was expected to be completely bound when UvrA monomer concentration was $40 \mathrm{nM}$ or higher. This prediction was observed when wild-type UvrA or never-been-crosslinked H750C UvrA was used (Supplementary Fig. 5). However, the crosslinked H750C UvrA is only able to bind less than $50 \%$ of the damaged DNA at $50 \mathrm{nM}$ protein concentration (Fig. 3A, 3C). Reversal of the disulfide crosslink by treatment with $\beta-M E$ restored the ability of H750C UvrA to bind to damaged DNA to the levels similar to those observed with wild-type UvrA (more than $80 \%$ of DNA bound at $50 \mathrm{nM}$ protein, Fig. 3B, and $3 \mathrm{C})$. The different amounts of complex formation with damaged DNA by crosslinked and crosslink-reversed H750C UvrA were observed at the protein concentrations between 5-50 nM (Fig. 3C). At concentrations of $100 \mathrm{nM}$ or greater, both crosslinked and crosslink-reversed species bound damaged DNA completely. We speculate that this could be due to complex formation between damaged DNA and the $\sim 20 \%$ of H750C UvrA that remained uncrosslinked (Fig. 2D), and likely establishes a limit to our assay. In contrast to the behavior on damaged DNA, H750C UvrA appears to bind native DNA with the same affinity regardless of the presence of 
the disulfide crosslink (Fig. 3D-F and Supplementary Fig. 4), at the levels comparable to that observed with wild-type UvrA (Supplementary Fig. 6).

\subsection{ATP hydrolysis by UvrA is abolished by restricting motion of the Zn3hp}

We next investigated whether the flexibility of the Zn3hp is required for ATP hydrolysis by UvrA. To this end, the ATPase activity of the crosslinked and crosslinkreversed H750C UvrA was measured using a coupled-enzyme assay system consisting of pyruvate kinase and lactate dehydrogenase, in which ATP hydrolysis is coupled to oxidation of NADH $[23,24]$. Since the ATPase activity of BstUvrA is stimulated by DNA [11], we performed the ATPase assay both in the presence and absence of DNA.

Our measurements revealed that the crosslinked H750C UvrA has lost its capacity to hydrolyze ATP. In comparison to crosslink-reversed H750C UvrA, the disulfide-linked protein lost approximately $50 \%$ of its ATPase activity (Fig. 4 and Supplementary Fig. 7). This percentage decrease is proportional to the $50 \%$ crosslinked H750C UvrA that was used in this assay (Supplementary Fig. 7). Notably, reversal of the crosslinking restored the ATPase activity to a level comparable to that of wild-type UvrA. These measurements indicated that crosslinking abolished the ATPase activity of UvrA, and that the residual activity arose from the population of the H750C UvrA that had not become crosslinked. The influence of the disulfide crosslink was evident without regard to the presence of DNA. The observation that ATPase activity could be disrupted by the disulfide crosslinking of $\mathrm{H} 750 \mathrm{C}$ UvrA, and then restored by the removal of the linkage establishes a connection between the mobility of the Zn3hp and the hydrolysis of ATP.

\subsection{ATP hydrolysis mediates the movements of the Zn3hp}

A variety of conformational changes in UvrA have been proposed to be involved in the early steps of NER and be triggered by DNA substrates, UvrB, and ATP $[12,15,25]$. To investigate whether these factors affect the conformational 
change of the Zn3hp, we measured the crosslinking efficiency of $\mathrm{H} 750 \mathrm{C}$ UvrA in the presence and absence of damaged and undamaged DNA, nucleotides, and UvrB.

Crosslinking analysis showed that both DNA and ATP hydrolysis affect the switching between the hairpin-closed and hairpin-open conformations of the Zn3hp. The presence of DNA reduced percentage of crosslinking to about 50\% (Fig. 5A). This increase in the uncrosslinked $\mathrm{H} 750 \mathrm{C}$ UvrA population is consistent with the structure of the UvrA-DNA complex (Fig. 2B), which indicates that the Zn3hp of each UvrA protomer needs to rotate away from each other and adopt the hairpin-open conformation to accommodate the DNA [13]. However, when ATP was added to the reaction, the crosslinked population increased to $90 \%$ regardless of whether DNA was present. Addition of ADP, which mimics the condition after ATP hydrolysis, also resulted in the same level of crosslinking as that observed with ATP (Supplementary Fig. 8A). Our crosslinking results suggest that when nucleotide (ATP or ADP) was added to the crosslinking reaction, UvrA adopts a conformation that is consistent with the ADP-bound, hairpin-closed structure in which the Zn3hp from each protomer are in close proximity (Fig. 2A) [11].

\subsection{ATP hydrolysis at the distal nucleotide binding site regulates the Zn $3 \mathrm{hp}$ movement}

UvrA possesses two non-identical nucleotide binding sites, designated as proximal and distal sites [11]. The exact role of each nucleotide binding site is still controversial. Studies of two single-site E. coli mutants showed that both mutants are deficient in damage repair in vivo $[2,22,26]$. Sancar and colleagues showed that although both ATPase mutants could bind damaged DNA, their UvrB-loading activity was dramatically reduced [26]. However, evidence from the Grossman group revealed that only the distal site mutant lost the damage incision ability, while the proximal site mutant was still able to initiate damage incision [27]. Results from the Goosen group showed that the efficiency of damage incision of the proximal site mutant was similar to that of wild-type UvrA; and while the distal site mutant could not repair the damage in a 50-bp DNA substrate, its repair ability was rescued by increasing the length of DNA [22]. In addition, we have recently showed that 
mutation of the proximal nucleotide binding site partially disrupts UvrA-UvrB interaction [12].

To investigate the involvement of each nucleotide binding site in the movement of the Zn3hp, the ATPase activity of each nucleotide binding site was inactivated by substituting K37 and $\mathrm{K} 643$ in the respective Walker A motif with alanine. Such alanine substitutions have been used to study other ATPases such as SMC [28], DMC1 [29], BmrA [30], and MalK transporter [31]. These mutations are expected to abolish ATP binding at the mutated site. The resulting mutants have drastically reduced ATPase activities (Supplementary Fig. 9), consistent with previous studies $[2,22,26]$.

Similar to what was observed with the ATPase wild-type (H750C) UvrA, addition of ATP or ADP increases the crosslinking efficiency of the proximal site mutant (K37A/H750C) by about two folds in DNA-containing conditions (Fig. 5B and Supplementary Fig. 7B). In contrast, the crosslinking of the distal site mutant (K643A/H750C) in the presence of DNA was not restored by the addition of ATP (Fig. 5B) or ADP (Supplementary Fig. 8B). Therefore, it appears that mutation at the distal site either prevents the Zn3hp from adopting the closed conformation, or abolishes the movement of the Zn3hp.

\subsection{Flexibility of the Zn3hp is essential for UvrB loading}

We next assessed the influence of restricting the mobility of the Zn3hp on the UvrA-mediated loading of UvrB [32, 33], which occurs after the initial lesion binding by UvrA $\mathrm{UvrB}_{2}$ complex. To this end, UvrB loading assays were performed using the crosslinked and crosslink-reversed H750C UvrA described above. Our results reveal that UvrB-DNA complex formation was dramatically decreased when the crosslinked H750C UvrA was used in the reaction compared to wild-type and the never-beencrosslinked H750C protein (Fig. 6A, 6C and Supplementary Fig. 10-11). However, when the disulfide linkage was reversed by the addition of $\beta-M E$, UvrB loading activity of H750C UvrA was restored (Fig. 6B-C and Supplementary Fig. 10-11). 


\section{Discussion}

\subsection{UvrA uses different DNA binding modes to interact with DNA}

The process of discriminating native from damaged DNA by UvrA is not well understood. Above, we have shown that restricting motion of the Zn3hp structural element reduces the affinity of $\mathrm{H} 750 \mathrm{C}$ UvrA for damaged DNA only, while interaction with native DNA appears unchanged.

We propose that UvrA adopts a bi-phasic DNA binding model in which two different DNA binding modes are employed to locate DNA lesions (Fig. 7). During an initial Zn3hp-independent phase, UvrA might interact with both damaged and undamaged DNA through residues around the DNA binding path. In part, this DNA binding path is lined with a group of residues from signature domain II consisting of positively charged residues and other residues that interact with the DNA in the DNA-bound structure (Supplementary Fig. 12A) [13]. Besides the signature II domain, this DNA binding path include residues from five other regions: the signature domain I, the insertion domain, and the three Zn-binding modules (Supplementary Fig. 12B). Many residues in these regions have been shown to be involved in DNA binding [12]. Previous studies showed that mutation of the positively charged residues in the signature domain II [11, 12], the insertion domain $[12,14,18]$, and the cluster of residues in all three Zn-binding modules [12] disrupted DNA binding. Furthermore, severe disruption of DNA binding was observed in the mutant in which its positively charged residues in the signature domain II were substituted by alanine [12].

Upon encountering damaged DNA, UvrA switches to a Zn3hp-dependent mode of binding that relies on the interaction between the lesion and the $\mathrm{Zn} 3 \mathrm{hp}$. We propose that the complex between the Zn3hp and the damaged DNA is stable while that between the Zn3hp and the undamaged DNA is not. While there is no direct contact between the Zn3hp and the DNA in the DNA-bound structure (Fig. 2B), the crystallographic evidence does not preclude the possibility that the Zn3hp may interact with DNA prior to the formation of a stable UvrA-DNA complex that is captured in the crystal structure. 
The model is well supported by our biochemical results. The apparent difference between the binding of damaged DNA with the crosslinked and the uncrosslinked protein suggested that, unlike the uncrosslinked UvrA which binds damaged DNA using both DNA binding modes, the crosslinked UvrA can only interact with damaged DNA through the electrostatic Zn3hp-independent interactions since the crosslinking traps the tips of the hairpins in the hairpin-closed conformation, making them inaccessible to DNA. In addition, since the electrostatic interactions occur during the initial contact with all types of dsDNA, there was no difference between binding of undamaged DNA with the crosslinked and the uncrosslinked protein (Fig. 3).

\subsection{The Zn3hp plays critical roles during the early steps of NER}

The different properties of the crosslinked $\mathrm{H} 750 \mathrm{C}$ UvrA and the $\Delta \mathrm{Zn} 3 \mathrm{hp}$ mutant $[17,18]$ highlight the importance of the Zn3hp in the initial steps of the NER cascade. From our results, restricting the movement of the Zn3hp almost completely abolished the three activities of UvrA that are essential for NER, namely, binding to damaged DNA, hydrolysis of ATP, and loading of UvrB to form pre-incision complex. However, previous study using UvrA from $B$. caldotenax, whose sequence is $97.8 \%$ identical to that of BstUvrA, shows that the $\triangle \mathrm{Zn} 3 \mathrm{hp}$ mutant remains partially functional [17]. Most strikingly, DNA binding activities of the $\Delta \mathrm{Zn3hp}$ mutant and the crosslinked $\mathrm{H} 750 \mathrm{C}$ UvrA are different. While the crosslinking of the Zn3hp decreased the affinity of $\mathrm{H} 750 \mathrm{C}$ UvrA for damaged DNA, the deletion of the Zn3hp increases binding to both damaged and undamaged DNA. We reason that the deletion of the Zn3hp makes the DNA-binding path highly accessible to all types of DNA and the specificity for damaged DNA is, therefore, compromised due to the lack of the Zn3hp, which is the key structural element for damage sensing.

Our disulfide crosslinking and biochemical assays of crosslinked H750C UvrA establish the relationship between ATP hydrolysis and the conformational change of the Zn3hp. Restricting the movement of the Zn3hp by disulfide crosslinking completely inhibits ATPase activity of $\mathrm{H} 750 \mathrm{C}$ UvrA (Fig. 4). In contrast, the $\triangle \mathrm{Zn} 3 \mathrm{hp}$ mutant, which can freely undergo conformational change, has comparable ATPase 
activity to wild-type [17]. The loss of the ATPase activity when a conformational change at a site distant from the ATPase active site was restricted has also been observed in Msh2-Msh6, another member of the ABC superfamily [34]. The Msh2Msh6 complex couples ATP hydrolysis to a conformational change within its Cterminal region. When the conformational change in the C-terminal region was prevented using disulfide crosslinking, Msh2-Msh6 exhibited reduced affinity for ATP and a loss-of-function phenotype.

The UvrB loading ability of UvrA is also inhibited by restricting the movement of the Zn3hp element, but not by deletion of the $\mathrm{Zn3hp.} \mathrm{This} \mathrm{result} \mathrm{is} \mathrm{not}$ unexpected since UvrB loading takes place after UvrA has identified the lesion. Our observation that dynamics of the Zn3hp element are required for UvrB loading implies existence of a precisely orchestrated set of events from lesion recognition to UvrB loading that must be executed in sequence and cannot be bypassed. In contrast, the $\Delta \mathrm{Zn} 3 \mathrm{hp}$ mutant can initiate the UvrB-DNA complex formation [17]. However, the loading activity of the deletion mutant decreased in the presence of undamaged DNA competitor since it lacks the Zn3hp, which is essential for damagespecific binding of UvrA.

The amino acid residues that are necessary for UvrA-UvrB interaction [12, 35] are solvent exposed in both the ADP-bound, hairpin-closed; and the DNA bound, hairpin-open UvrA structures (Supplementary Fig. 13); and are also expected to be solvent exposed in the crosslinked UvrA. Therefore, the ability of H750C UvrA to bind to UvrB is unlikely to be affected by crosslinking. Indeed, the presence of UvrB in the reaction had no effect on the crosslinking efficiency of H750C UvrA (Fig. 5).

\subsection{ATP hydrolysis at the distal site increases the dynamics of the Zn3hp}

To investigate the involvement of the proximal and distal nucleotide binding sites of UvrA in the movement of the Zn3hp, each of the sites was individually inactivated by alanine substitution of the Walker A lysine residue. The drastic decrease in crosslinking efficiency of the distal site mutant in the presence of DNA suggested that the distal site controls the movement of the Zn3hp. 
We proposed that ATP binding and hydrolysis at the distal site increases the dynamics of the Zn3hp such that the hairpins sample the hairpin-open and hairpinclosed conformations at an accelerated rate. In the ATPase wild-type (H750C) and the proximal site mutant, ATP or ADP significantly increased the percentage of crosslinking in the presence of both damaged and undamaged DNA. In contrast, such effect was not observed in the distal site mutant (Fig. 5 and Supplementary Fig. 8).

While the DNA binding assay, carried out in the presence of ATP, showed that the crosslinked H750C UvrA could not efficiently bind the damaged DNA (Fig. 3), crosslinking experiments showed that the crosslinking efficiency of the protein was not affected by the presence of damaged DNA if ATP was also present in the reaction (Fig.5). We propose that this apparent discrepancy could be explained as follows. In the DNA binding studies, the H750C UvrA was disulfide crosslinked prior to the assay. Restricting the Zn3hp in the hairpin-closed conformation prevents specific engagement with damaged DNA. In the crosslinking assay, however, H750C UvrA was not yet crosslinked when it was introduced into the reaction. During the assay, ATP would interact with UvrA at a faster rate than the DNA as diffusion rates are inversely proportional to molecular size [36] and the ATP concentration in the reaction was approximately 2000-fold higher than that of DNA. Once ATP hydrolysis at the distal site occurs, it increases the dynamics of the Zn3hp and raises the propensity at which the tips of the hairpins would adopt the hairpinclosed, crosslink-able conformation. Accordingly, the addition of ATP to the distal site mutant did not alter the extent of crosslinking due to the lack of ATP binding and hydrolysis.

It might appear counterintuitive that the distal site, which is located further away, exerts a greater influence on the dynamics of the Zn3hp than the closer proximal site. It has previously been shown, however, that the two types of sites are not independent $[22,26]$. We also observed that inactivation of the proximal site resulted in an almost complete loss of ATPase activity (Supplementary Fig. 9), indicating that the two sites function in a cooperative way. Nonetheless, our results are consistent with previous genetics and biochemical evidence. A distal site mutant 
lost the DNA repair ability in vivo [2, 22, 26], and exhibit impaired UvrB loading [22] and incision activities in vitro [2, 22].

\section{Conclusion}

Disulfide crosslinking using engineered cysteine residues provides insights into the role of conformational change of the $\beta$-hairpin in the third $\mathrm{Zn}$ module of UvrA (Zn3hp). Our findings suggest that the switch between the hairpin-open and hairpinclosed conformations of the Zn3hp is essential for damage sensing and mediating of the downstream cascade of the NER pathway. In addition, ATP hydrolysis at the distal nucleotide binding site regulates the movement of the Zn3hp, which is crucial for the initiation of damage verification and incision steps of NER.

\section{Acknowledgements}

We thank Rou-Jia Sung, Jirundon Yuvaniyama, and Pimchai Chaiyen for useful discussions and critical reading of the manuscript. This work was supported by grants from the Thailand Research Fund (MRG5680043) and the Royal Thai Government budget through Mahidol University (2558A11003398 and 2559A11003095) to DP, the National Science Foundation, USA (MCB 0918161 to DJ), and the Thailand Research Fund (RTA5980001) to Pimchai Chaiyen. TK is supported by the Science Achievement Scholarship of Thailand (SAST).

\section{References}

[1] S.J. Mazur, L. Grossman, Dimerization of Escherichia coli UvrA and its binding to undamaged and ultraviolet light damaged DNA, Biochemistry, 30 (1991) 4432-4443.

[2] S. Thiagalingam, L. Grossman, Both ATPase sites of Escherichia coli UvrA have functional roles in nucleotide excision repair, J. Biol. Chem., 266 (1991) 11395-11403.

[3] D.K. Orren, A. Sancar, Formation and enzymatic properties of the UvrB.DNA complex, J. Biol. Chem., 265 (1990) 15796-15803.

[4] G.F. Moolenaar, M.F. Herron, V. Monaco, G.A. van der Marel, J.H. van Boom, R. Visse, N. Goosen, The role of ATP binding and hydrolysis by UvrB during nucleotide excision repair, J. Biol. Chem., 275 (2000) 8044-8050. 
[5] A. Sancar, W.D. Rupp, A novel repair enzyme: UVRABC excision nuclease of Escherichia coli cuts a DNA strand on both sides of the damaged region, Cell, 33 (1983) 249-260.

[6] J.J. Truglio, D.L. Croteau, B. Van Houten, C. Kisker, Prokaryotic nucleotide excision repair: the UvrABC system, Chem. Rev., 106 (2006) 233-252.

[7] C. Kisker, J. Kuper, B. Van Houten, Prokaryotic nucleotide excision repair, Cold Spring Harb. Perspect. Biol., 5 (2013) a012591.

[8] R.F. Doolittle, M.S. Johnson, I. Husain, B. Van Houten, D.C. Thomas, A. Sancar, Domainal evolution of a prokaryotic DNA repair protein and its relationship to active-transport proteins, Nature, 323 (1986) 451-453.

[9] L. Schmitt, H. Benabdelhak, M.A. Blight, I.B. Holland, M.T. Stubbs, Crystal structure of the nucleotide-binding domain of the ABC-transporter haemolysin $B$ : identification of a variable region within $A B C$ helical domains, J. Mol. Biol., 330 (2003) 333-342.

[10] R. Gaudet, D.C. Wiley, Structure of the ABC ATPase domain of human TAP1, the transporter associated with antigen processing, The EMBO journal, 20 (2001) 4964-4972.

[11] D. Pakotiprapha, Y. Inuzuka, B.R. Bowman, G.F. Moolenaar, N. Goosen, D. Jeruzalmi, G.L. Verdine, Crystal structure of Bacillus stearothermophilus UvrA provides insight into ATP-modulated dimerization, UvrB interaction, and DNA binding, Mol. Cell, 29 (2008) 122-133.

[12] D. Pakotiprapha, M. Samuels, K. Shen, J.H. Hu, D. Jeruzalmi, Structure and mechanism of the UvrA-UvrB DNA damage sensor, Nat. Struct. Mol. Biol., 19 (2012) 291-298.

[13] M. Jaciuk, E. Nowak, K. Skowronek, A. Tanska, M. Nowotny, Structure of UvrA nucleotide excision repair protein in complex with modified DNA, Nat. Struct. Mol. Biol., 18 (2011) 191-197.

[14] J. Timmins, E. Gordon, S. Caria, G. Leonard, S. Acajjaoui, M.S. Kuo, V. Monchois, S. McSweeney, Structural and mutational analyses of Deinococcus radiodurans UvrA2 provide insight into DNA binding and damage recognition by UvrAs, Structure, 17 (2009) 547-558.

[15] F. Rossi, J.S. Khanduja, A. Bortoluzzi, J. Houghton, P. Sander, C. Guthlein, E.O. Davis, B. Springer, E.C. Bottger, A. Relini, A. Penco, K. Muniyappa, M. Rizzi, The biological and structural characterization of Mycobacterium tuberculosis UvrA provides novel insights into its mechanism of action, Nucleic Acids Res., 39 (2011) 7316-7328.

[16] G.P. Poornam, A. Matsumoto, H. Ishida, S. Hayward, A method for the analysis of domain movements in large biomolecular complexes, Proteins, 76 (2009) 201-212. 
[17] D.L. Croteau, M.J. DellaVecchia, H. Wang, R.J. Bienstock, M.A. Melton, B. Van Houten, The C-terminal zinc finger of UvrA does not bind DNA directly but regulates damage-specific DNA binding, J. Biol. Chem., 281 (2006) 26370-26381.

[18] K. Wagner, G.F. Moolenaar, N. Goosen, Role of the insertion domain and the zinc-finger motif of Escherichia coli UvrA in damage recognition and ATP hydrolysis, DNA repair, 10 (2011) 483-496.

[19] D.B. Craig, A.A. Dombkowski, Disulfide by Design 2.0: a web-based tool for disulfide engineering in proteins, BMC Bioinformatics, 14 (2013) 346.

[20] A.A. Dombkowski, Disulfide by Design: a computational method for the rational design of disulfide bonds in proteins, Bioinformatics, 19 (2003) 1852-1853.

[21] K. Wagner, G. Moolenaar, J. van Noort, N. Goosen, Single-molecule analysis reveals two separate DNA-binding domains in the Escherichia coli UvrA dimer, Nucleic Acids Res., 37 (2009) 1962-1972.

[22] K. Wagner, G.F. Moolenaar, N. Goosen, Role of the two ATPase domains of Escherichia coli UvrA in binding non-bulky DNA lesions and interaction with UvrB, DNA Repair (Amst), 9 (2010) 1176-1186.

[23] K. Kiianitsa, J.A. Solinger, W.D. Heyer, NADH-coupled microplate photometric assay for kinetic studies of ATP-hydrolyzing enzymes with low and high specific activities, Anal. Biochem., 321 (2003) 266-271.

[24] J.E. Lindsley, Use of a real-time, coupled assay to measure the ATPase activity of DNA topoisomerase II, Methods Mol. Biol., 95 (2001) 57-64.

[25] N. Goosen, G.F. Moolenaar, Role of ATP hydrolysis by UvrA and UvrB during nucleotide excision repair, Res. Microbiol., 152 (2001) 401-409.

[26] G.M. Myles, J.E. Hearst, A. Sancar, Site-specific mutagenesis of conserved residues within Walker $A$ and $B$ sequences of Escherichia coli UvrA protein, Biochemistry, 30 (1991) 3824-3834.

[27] S. Thiagalingam, L. Grossman, The multiple roles for ATP in the Escherichia coli UvrABC endonuclease-catalyzed incision reaction, J. Biol. Chem., 268 (1993) 18382-18389.

[28] A. Lammens, A. Schele, K.P. Hopfner, Structural biochemistry of ATPdriven dimerization and DNA-stimulated activation of SMC ATPases, Curr. Biol., 14 (2004) 1778-1782.

[29] D. Sharma, A.F. Say, L.L. Ledford, A.J. Hughes, H.A. Sehorn, D.S. Dwyer, M.G. Sehorn, Role of the conserved lysine within the Walker A motif of human DMC1, DNA Repair (Amst), 12 (2013) 53-62. 
[30] C. Orelle, F. Gubellini, A. Durand, S. Marco, D. Levy, P. Gros, A. Di Pietro, J.M. Jault, Conformational change induced by ATP binding in the multidrug ATP-binding cassette transporter BmrA, Biochemistry, 47 (2008) 2404-2412.

[31] C.H. Panagiotidis, M. Reyes, A. Sievertsen, W. Boos, H.A. Shuman, Characterization of the structural requirements for assembly and nucleotide binding of an ATP-binding cassette transporter. The maltose transport system of Escherichia coli, J. Biol. Chem., 268 (1993) 23685-23696.

[32] B. Van Houten, H. Gamper, A. Sancar, J.E. Hearst, DNase I footprint of ABC excinuclease, J. Biol. Chem., 262 (1987) 13180-13187.

[33] B.M. Kacinski, W.D. Rupp, E. coli uvrB protein binds to DNA in the presence of uvrA protein, Nature, 294 (1981) 480-481.

[34] V.V. Hargreaves, C.D. Putnam, R.D. Kolodner, Engineered disulfideforming amino acid substitutions interfere with a conformational change in the mismatch recognition complex Msh2-Msh6 required for mismatch repair, J. Biol. Chem., 287 (2012) 41232-41244.

[35] D. Pakotiprapha, Y. Liu, G.L. Verdine, D. Jeruzalmi, A structural model for the damage-sensing complex in bacterial nucleotide excision repair, J. Biol. Chem., 284 (2009) 12837-12844.

[36] C.C. Miller, The Stokes-Einstein Law for Diffusion in Solution, Proceedings of the Royal Society of London. Series A, Containing Papers of a Mathematical and Physical Character, 106 (1924) 724-749.

Figure legends

Fig. 1. Three conformations of $\mathrm{Zn} 3 \mathrm{hp}$ are captured in UvrA structures. Domain movement analysis of nucleotide-binding domain II, consisting of signature domain II (Sig-II, teal) and ATP-binding domain II (ATP-II, orange), reveals three conformations of the Zn3hp (blue) (Supplementary Table. 1 and Supplementary Fig. 1). Hairpinclosed configuration is captured in both the open-tray (2R6F, 3ZQJ, 2VF7, and 2VF8) and closed-groove (3UWX) dimer conformations. Hairpin-open configuration is observed in the DNA-bound structure $(3 \mathrm{PIH})$ which is in the open-tray dimer. Intermediate configuration between the hairpin-closed and the hairpin-opens conformation is detected in the truncated UvrA structure (3UX8), whose hairpin is disordered in the structure and is extrapolated from the position of the observed 
residues at the base of the Zn3hp in the structure. The structures are shown in both top view (upper panel) and side view (lower panel).

Fig. 2. Signature domain II and Zn3hp undergo conformational change upon DNA binding. (A) ADP-bound UvrA structure (2R6F) shows the hairpin-closed conformation of the Zn3hp. The two UvrA protomers are colored in different shades of gray. Signature domain II, in which Zn3hp is located, is shown as ribbon diagram and colored in pink, with the $\mathrm{Zn3hp} \mathrm{in} \mathrm{hot} \mathrm{pink,} \mathrm{and} \mathrm{Zn}$ atom in gray. $\mathrm{H} 750$ residue at the tip of the Zn3hp, mutated to cysteine for disulfide crosslinking, is shown as a sphere. (B) DNA-bound UvrA structure (3PIH) displays the hairpin-open conformation of the Zn3hp. Each component in this structure is shown as described in $2 \mathrm{~A}$ except that the signature domain II is colored in blue. The sphere at the tip of Zn3hp in this structure shows the position of L730, which is, from amino acid sequence alignment, equivalent to $\mathrm{H} 750$ in the ADP-bound structure. (C) Superposition of ATP binding domain II of the DNA-bound structure $(3 \mathrm{PIH})$ onto that of the ADP-bound structure (2R6F) reveals that in the presence of DNA, signature domain II rotates $18.5^{\circ}$ from the position observed in the ADP-bound structure. As a result, the Zn3hp of the DNA-bound structure moves $21 \AA$ away from the dimer interface. (D) H750C UvrA was incubated at room temperature for $24 \mathrm{~h}$ in $\beta$-ME-free condition. The crosslinking efficiency of $\mathrm{H} 750 \mathrm{C}$ UvrA was about $80 \%$ according to the band intensities on non-reducing SDS-PAGE.

Fig. 3. The movement of $\mathrm{Zn} 3 \mathrm{hp}$ is required for damage-specific binding. DNA binding ability of crosslinked and crosslink-reversed $\mathrm{H} 750 \mathrm{C}$ UvrA was assayed using EMSA by titrating $20 \mathrm{nM}$ DNA substrate with 0-200 nM H750C UvrA. Binding between the damaged DNA and $(A)$ crosslinked $\mathrm{H} 750 \mathrm{C}$ UvrA or $(B)$ crosslinkreversed $\mathrm{H} 750 \mathrm{C}$ UvrA. (C) Comparison of percent DNA bound from the panel $A$ and $B$. Binding between the undamaged DNA and $(D)$ crosslinked H750C UvrA or $(E)$ crosslink-reversed H750C UvrA. (F) Comparison of percent DNA bound from the panel $\mathrm{D}$ and $\mathrm{E}$. The percent bound was calculated as intensity of UvrA-DNA band $\mathrm{x}$ $100 /$ total intensities. The data are reported by mean \pm standard error $(n=3)$. 
Fig. 4. The movement of $\mathrm{Zn} 3 \mathrm{hp}$ is required for ATP hydrolysis. Wild-type UvrA and $\mathrm{H} 750 \mathrm{C}$ UvrA were incubated in $\beta$-ME-free buffer at $4^{\circ} \mathrm{C}$ for one week, resulting in $50 \%$ crosslinked $\mathrm{H} 750 \mathrm{C}$ UvrA (Supplementary Fig. 7 ). In the condition with $\beta$-ME (+BME), $10 \mathrm{mM}$ of $\beta$-ME was added to the proteins for 2 hours before assay. The proteins were assayed for its ATPase activity using a coupled enzyme system, in which ATP hydrolysis is coupled with NADH oxidation. The turnover number was calculated as $\mathrm{mol}$ ATP $/ \mathrm{min} / \mathrm{mol}$ UvrA. The data are reported as mean \pm standard error $(n=3)$.

Fig. 5. ATP hydrolysis at the distal ATPase active site controls the transition between the open and closed conformations of Zn3hp. (A) Percent crosslinking of ATPase wild-type (H750C) UvrA in the presence of various NER factors (damaged or undamaged DNA, UvrB, and ATP). The data are reported as mean \pm standard error $(n=5)$. (B) Comparison of percent crosslinking of ATPase wild-type (H750C) and active site mutants $(\mathrm{H} 750 \mathrm{C} / \mathrm{K} 37 \mathrm{~A}$ and $\mathrm{H} 750 \mathrm{C} / \mathrm{K} 643 \mathrm{~A})$. The data are reported as mean \pm standard error $(n=5)$.

Fig. 6. Restricting the conformational change of Zn3hp disrupts UvrB loading activity. UvrB loading activity of $\mathrm{H} 750 \mathrm{C}$ UvrA was investigated by titrating $10 \mathrm{nM}$ DNA substrate and $5 \mathrm{nM} \mathrm{H750C}$ UvrA with 0-200 nM UvrB. Formation of UvrB-DNA complex was analyzed by EMSA. UvrB loading activity of $(A)$ crosslinked $\mathrm{H} 750 \mathrm{C}$ UvrA and (B) crosslink-reversed H750C UvrA. (C) Percent of UvrB-DNA complex was calculated as intensity of UvrB-DNA band $\times 100 /$ total intensities. The data are reported as mean \pm standard error $(n=3)$.

Fig. 7. UvrA employs different DNA binding modes to interact with the DNA. (A) Model for binding between damaged DNA and UvrA. Left: During initial DNA binding UvrA interacts with DNA using Zn3hp-independent binding mode. This binding mode relies on the interaction between DNA and DNA binding path of UvrA, 
which is composed of positively charged residues from signature domain II, insertion domain, and clusters of residues from three Zn-binding modules. Right: Zn3hpdependent binding mode stabilizes the damaged DNA-UvrA complex. (B) Model for binding between undamaged DNA and UvrA. Left: Similar to the left panel in 6A, Zn3hp-independent mode of binding also interacts with the normal DNA during initial stage of binding. Right: Zn3hp-dependent binding mode does not stabilize undamaged DNA-UvrA complex. 


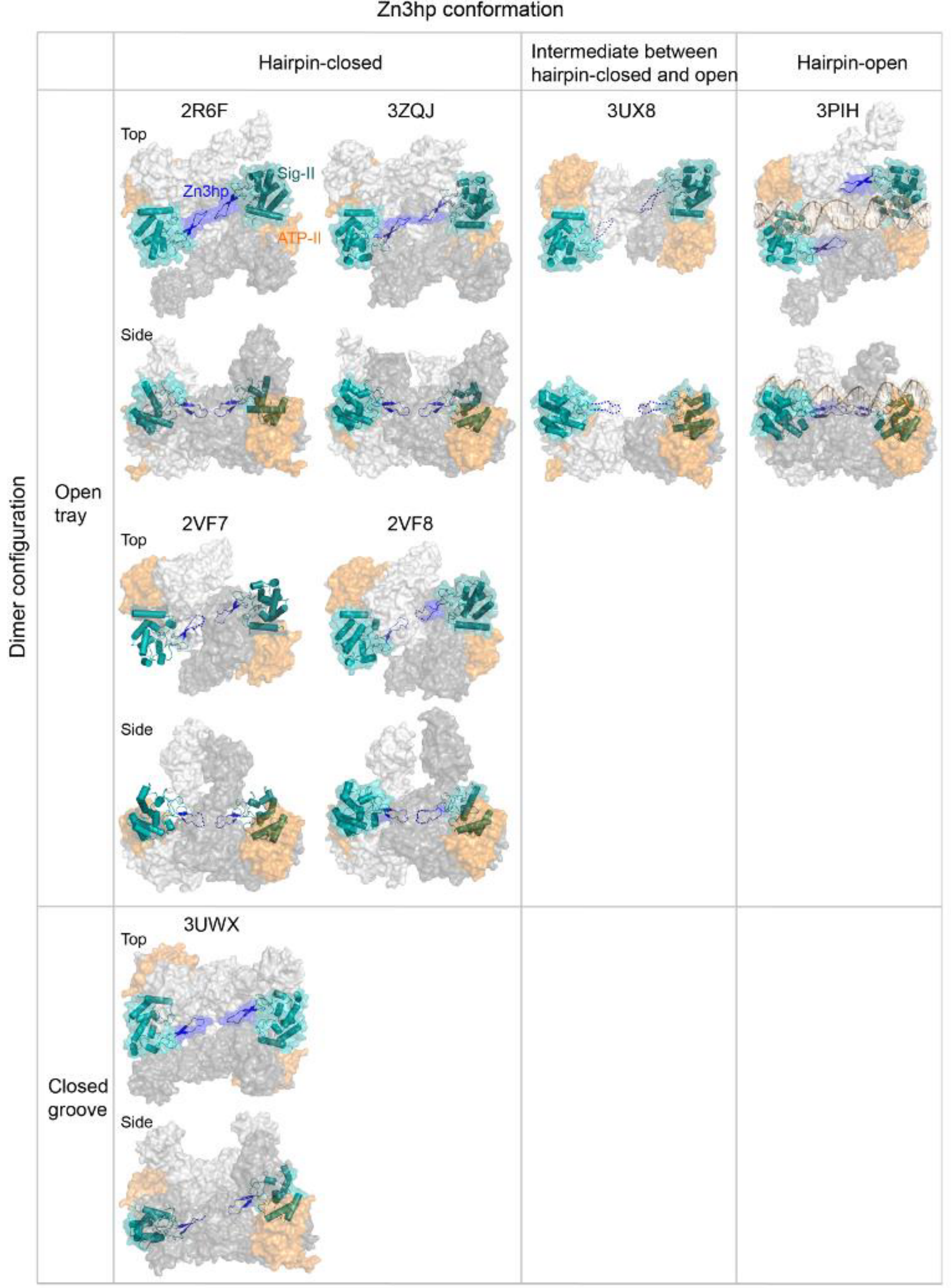

Zn3hp of 2VF7, 2VF8, and $3 U W X$ is disordered and is extrapolated (shown in dashed line).

Figure 1 


\section{A Hairpin-closed}

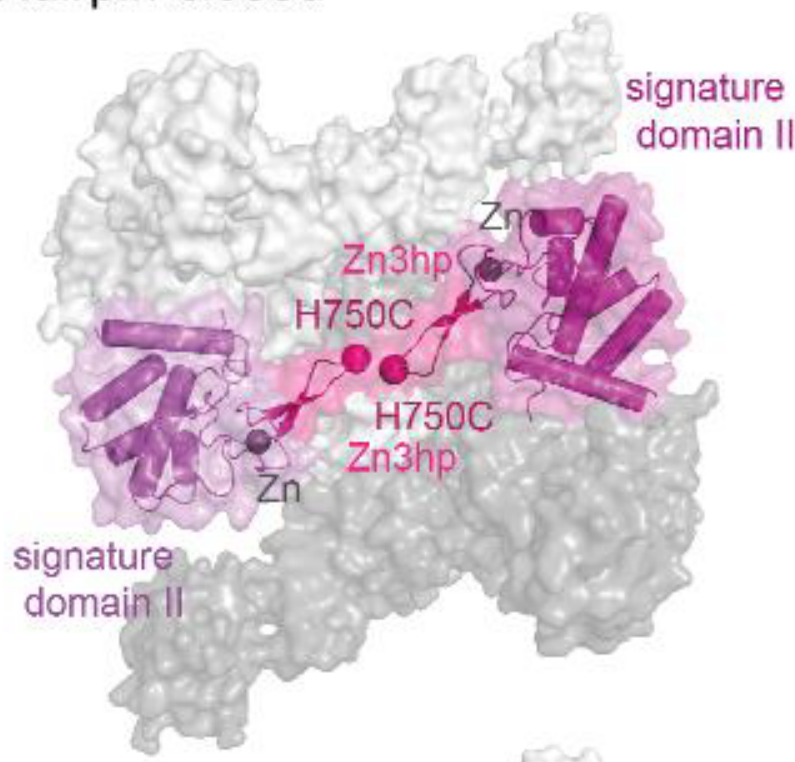

\section{B Hairpin-open}

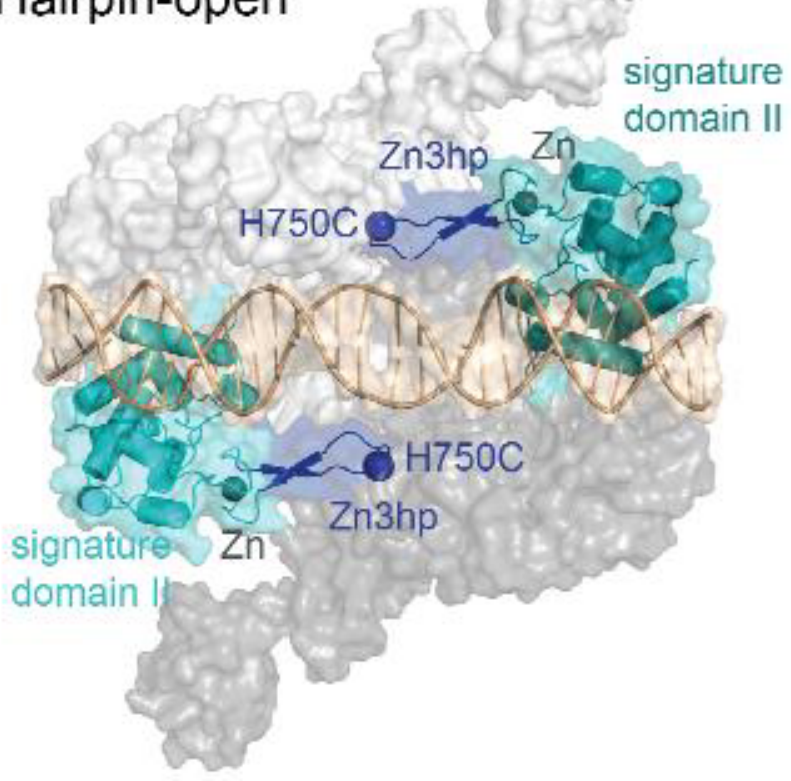

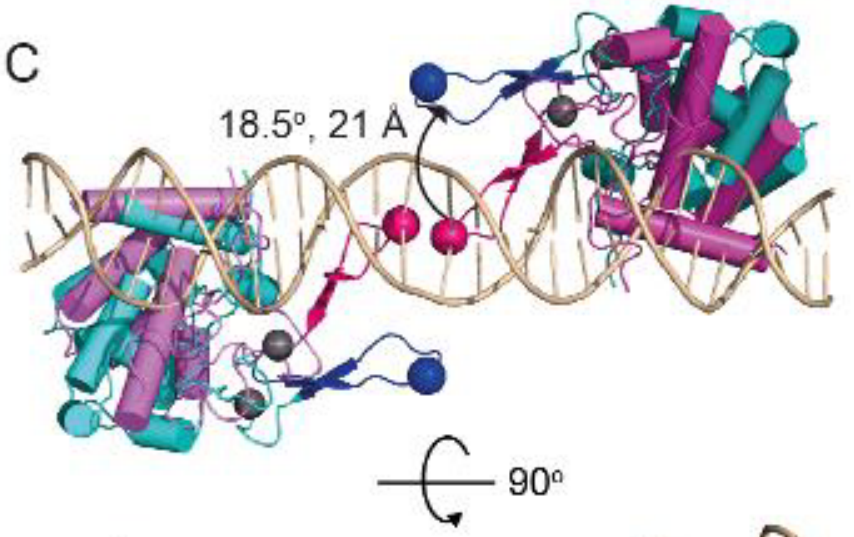

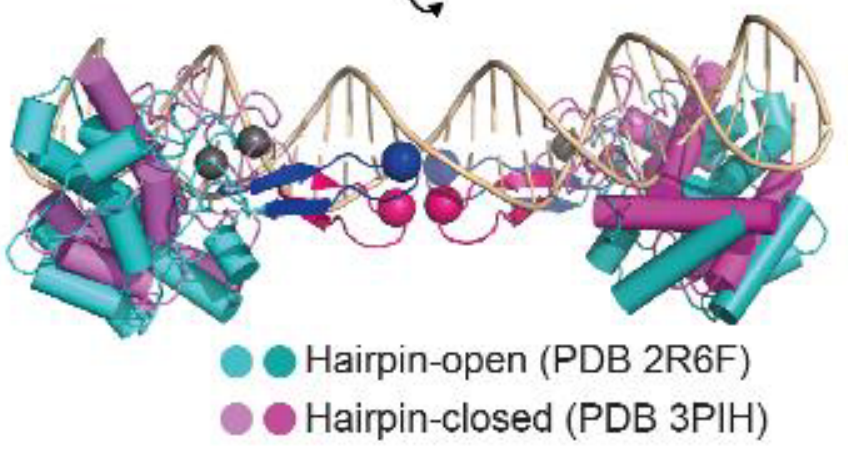

D

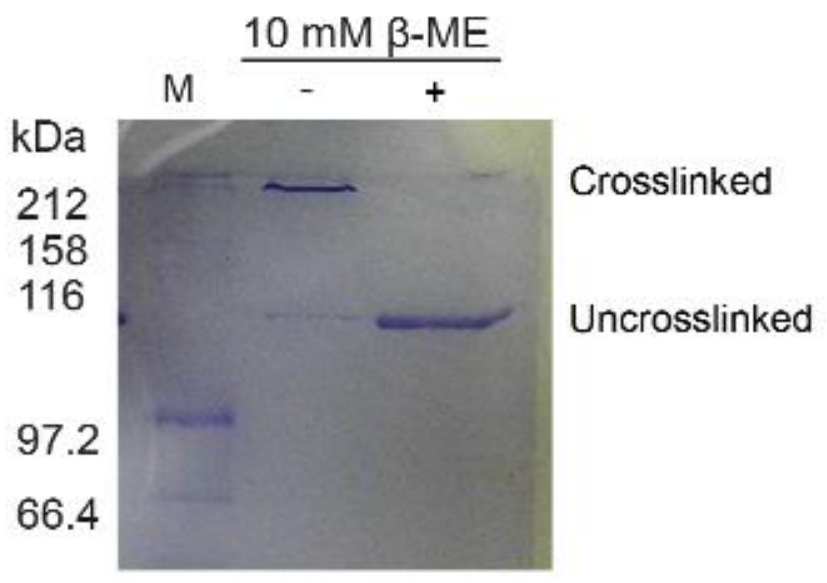

\section{Figure 2}




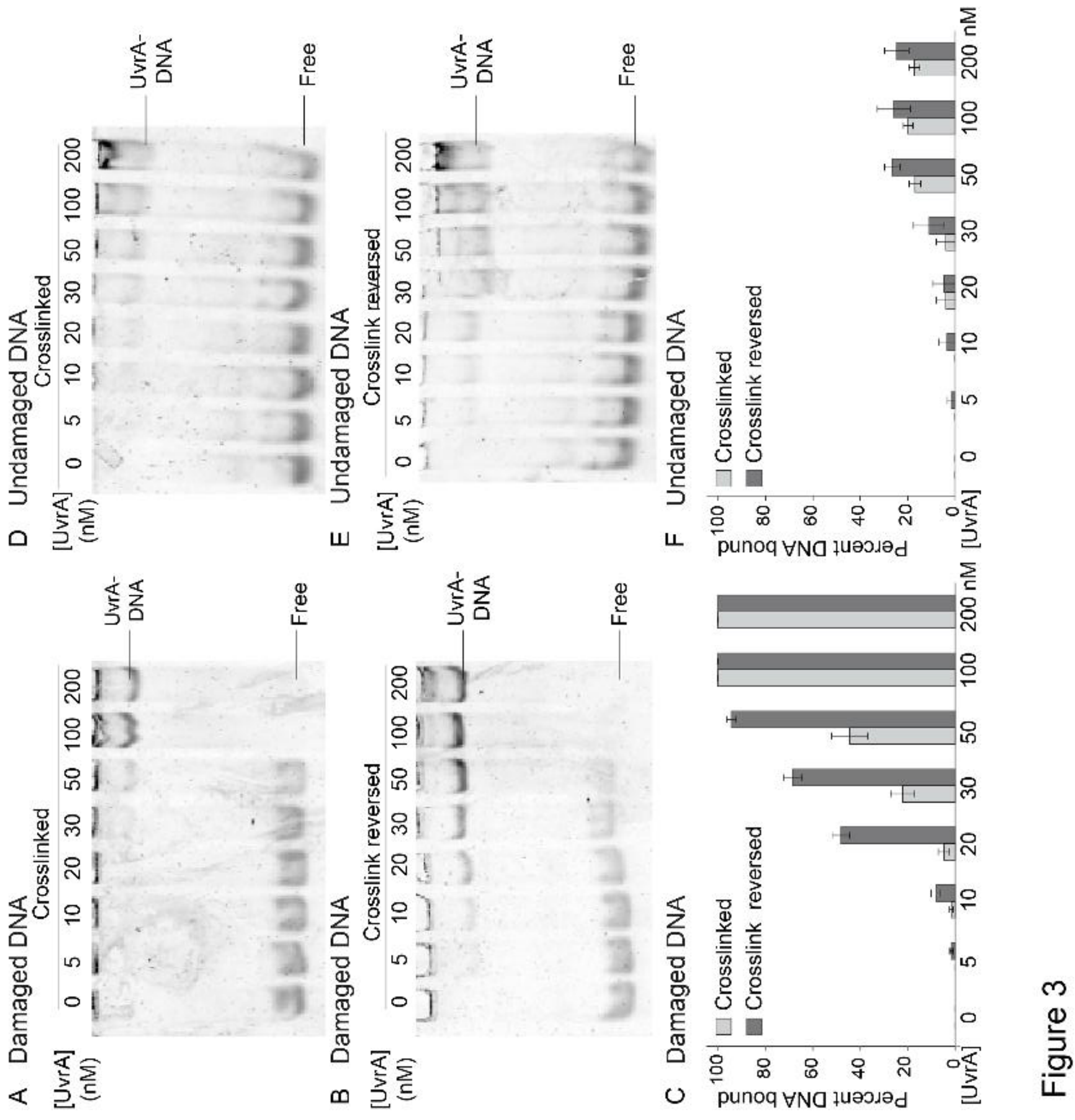




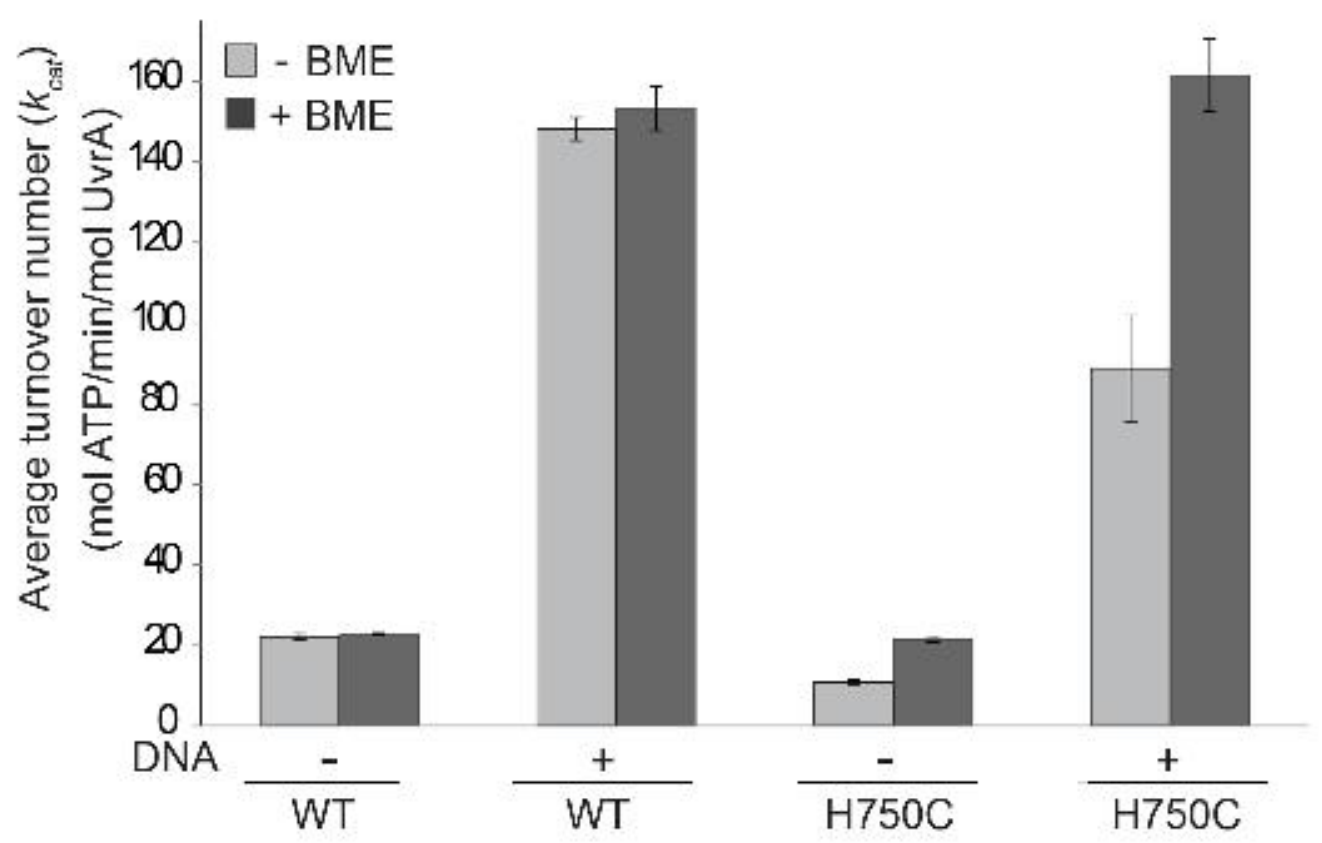

Figure 4 


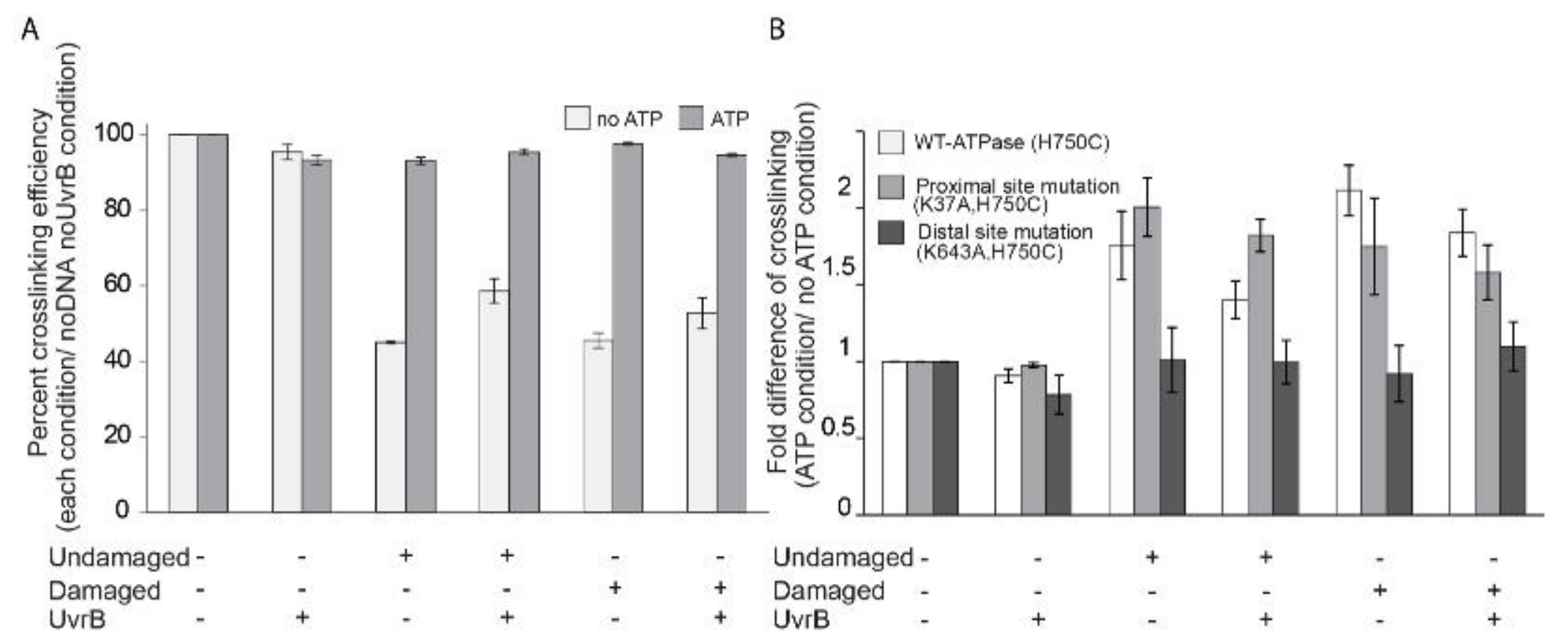

Figure 5 
A Crosslinked UvrA [UvrA] (nM) 0 [UvrB] (nM) $0 \quad \begin{array}{llllllll}0 & 5 & 10 & 20 & 50 & 100 & 200 & 0\end{array}$

C

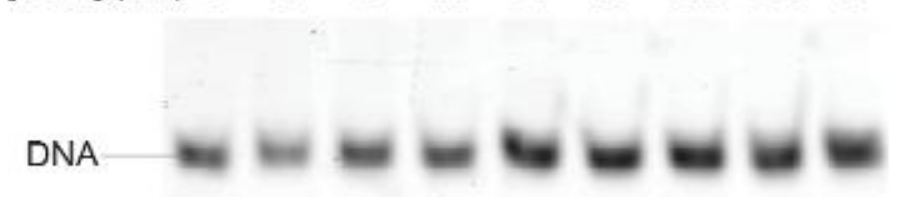

B Crosslink reversed UvrA

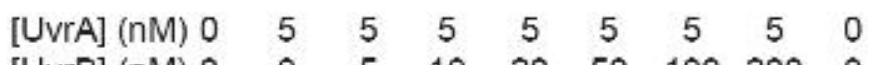

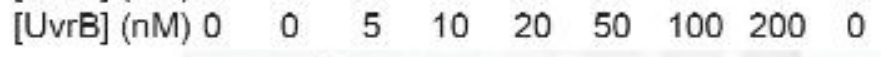
UvrB-DNA

DNAFigure 6

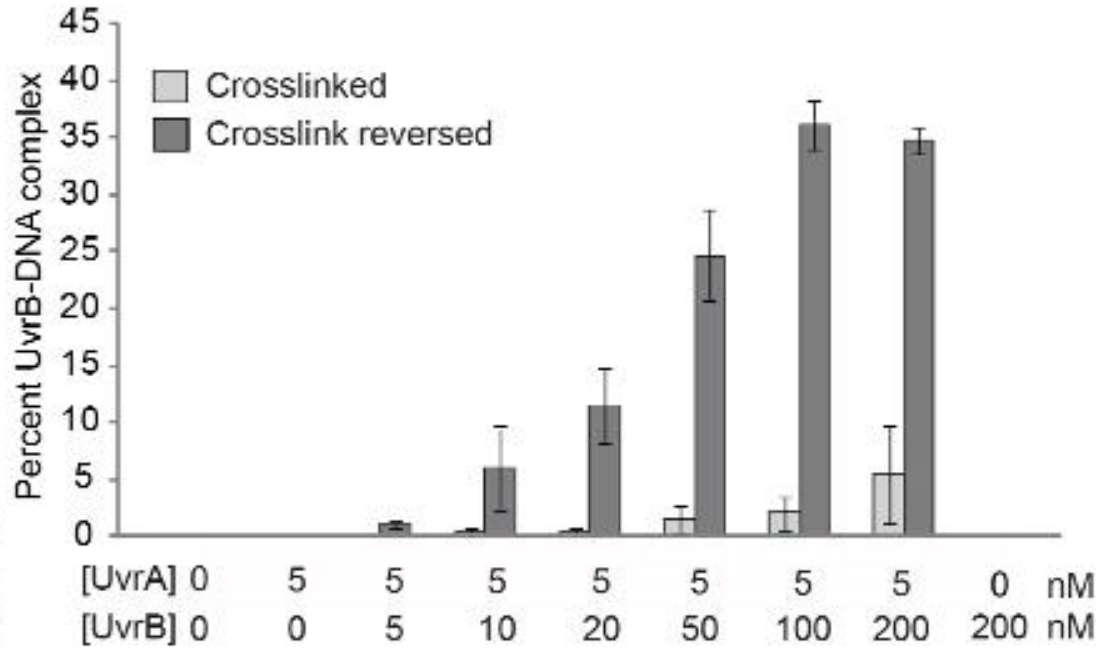


A Binding to damaged DNA

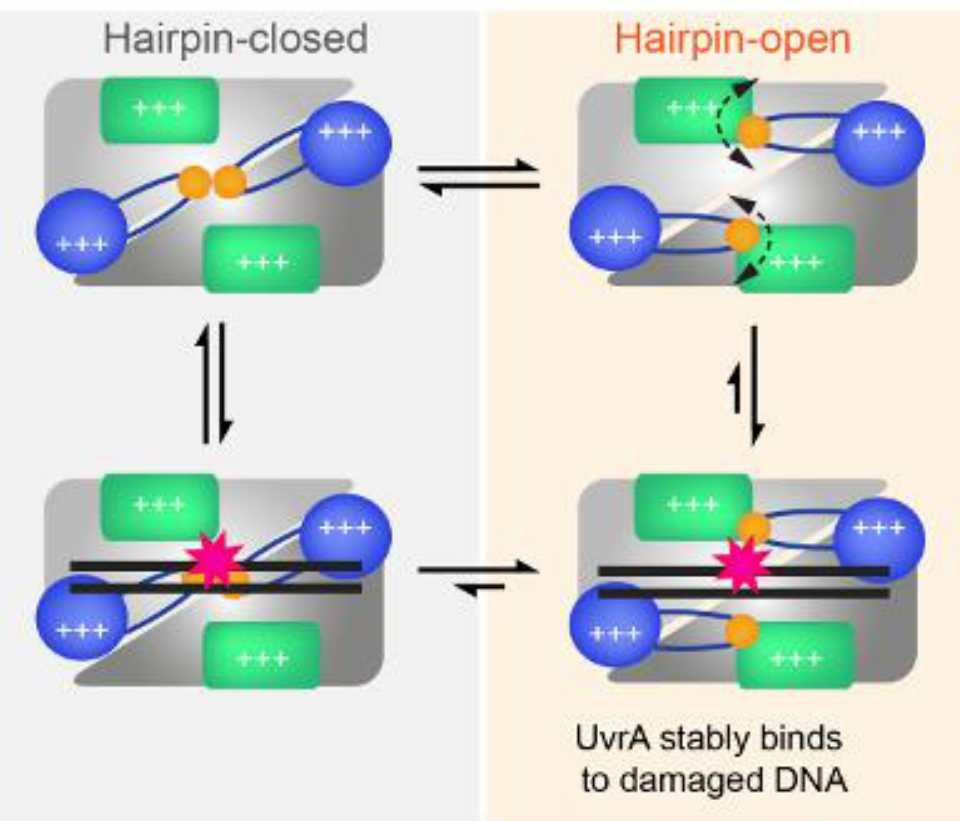

Binding mode 1

Zn3hp-independent
Binding mode 2 Zn3hp-dependent
$B$ Binding to undamaged DNA

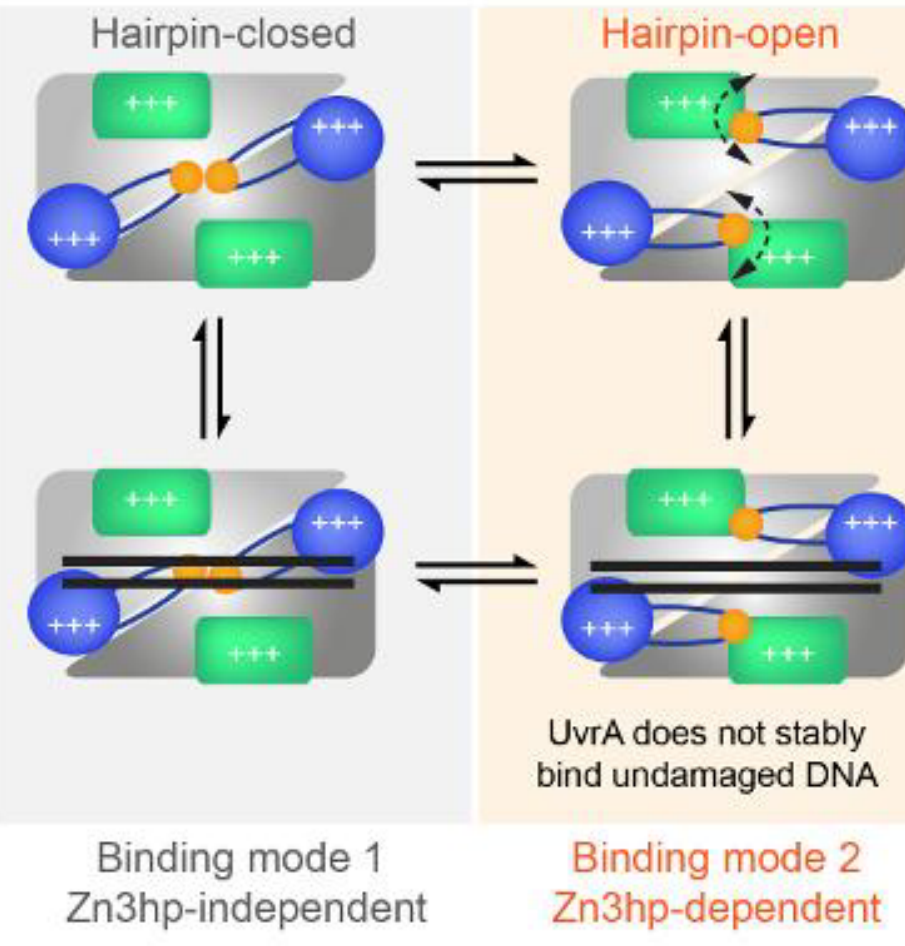

\section{UvrA Signature domain II}

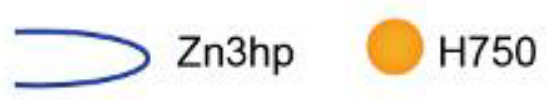

Insertion domain 